\title{
Public use of external defibrillator in Hangzhou of China
}

\author{
Jin Xiao Sheng ${ }^{1}$, Ye Kan², Zhang Gai ${ }^{3}$, Zhang Hao ${ }^{4}$ \\ ${ }^{1}$ Professor, ${ }^{2,3,4}$ Associate Professor, Department of Emergency Medicine, Medical Emergency Service of Wenzhou, \\ Zhejiang Province, China
}

Background: Ventricular fibrillation (VF) is one of the causes of out-of-hospital cardiac arrest (OHCA). The increase in survival after out-of-hospital cardiac arrest is closely related to early detection and shortening the first defibrillation time. The implementation of AEDs deployment plan in public places in Hangzhou City provides an opportunity to improve the survival rate after out-of-hospital cardiac arrest, and the benefits and potentials are enormous. Aims and Objective: Placing AEDs in public areas can effectively treat patients with pre-hospital cardiac arrest, by evaluating the configuration and usage of public AEDs in Hangzhou during the past five years, to provide the basis for improving the public areas' configuration AEDs network layout and related training management. Materials and Methods: The number of AEDs in public areas, the use of AEDs and the treatment effect in Hangzhou city from 2015 to 2020 were collected. Results: The number of AEDs in public areas, the use of AEDs and the treatment effect in Hangzhou city from 2015 to 2020 were collected. In 5 years, a total of 1201 AEDs were configured, Placed in densely populated areas such as transportation hubs, schools, and scenic spots as the main locations. 32 patients suffered prehospital cardiac arrest and used AEDs, the average age of the patients was $40.56 \pm 17.20$, and the ratio of male to female was $3.57: 1$, In 26 cases, the initial heart rhythm was ventricular fibrillation and defibrillation, Before the first aid personnel arrived, the first witnesses Implement rescue, 22 patients with ventricular fibrillation were resuscitated successfully, 10 cases failed to ROSC. In 6 patients with suspected cardiac arrest, there was no electric shock defibrillation, and the device correctly indicates that the problem is not caused by ventricular fibrillation, In 4 cases, there was no defibrillating rhythm. Conclusion: AEDs in public areas are effectively used to assist in the treatment of patients with cardiac arrest; It can increase the rate of main circulation recovery. We will further increase the number of AEDs in public places, promote first aid training programs for non-professionals, Improving the public health emergency network system is essential to improve the prognosis of patients with cardiac arrest.

Key words: Out-of-hospital cardiac arrest; AEDs; Public Areas defibrillation; Defibrillators

\section{Access this article online}

Website:

http://nepjol.info/index.php/AJMS DOI: 10.3126/ajms.v12i6.34835

E-ISSN: 2091-0576

P-ISSN: 2467-9100

Copyright (c) 2021 Asian Journal of Medical Sciences

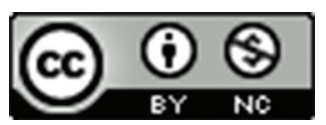

This work is licensed under a Creative Commons Attribution-NonCommercial 4.0 International License.

\section{INTRODUCTION}

Out of hospital cardiac arrest (OHCA) is a major health problem associated with cardiovascular disease. ${ }^{1,2}$ In China, it is estimated that 544,000 individuals suffer from OHCA each year, but less than $1 \%$ of them survive on-site or at discharge. Research has suggested that each minute of delay in resuscitation equals toa $10 \%$ decrease inosuria. ${ }^{3}$ Early defibrillation is essential to improve survival rates. The use of automatic external defibrillators (AEDs) has been shown to increase survival rates up to $75 \%{ }^{4,5}$ Although the rapid use of defibrillators is highly reversible, but even with immediate CPR, Ventricular fibrillation is still fatal within a few minutes. According to reports, less than $3 \%$ of OHCA patients are defibrillated before emergency medical services (EMS) arrive. ${ }^{6,7}$ Public access to the automated external 
defibrillator (AEDs) is an effective approach for rapid and early defibrillation. ${ }^{8,9,10}$ After the corresponding training, non-medical personnel (for example, flight attendants or security personnel) can use AEDs in the workplace, To save the lives of patients. Starting in May 2015, Hangzhou city started to promote the public areas' defibrillator program. Now we have made the following evaluation on the use of AEDs in the past five years.

\section{MATERIALS AND METHODS}

\section{Setting}

Hangzhou is located in the Yangtze River Delta region, which is one of the most developed, most dynamic and most potential areas in Chinese economy and is rapidly rising as the world's sixth largest city agglomeration. Since 2015, AEDs are placed in places with heavy traffic (airports, stations, subways), shopping malls with dense crowds, schools, and hotels. For example, Hangzhou Railway Station covers an area of 400,000 square meters. The average annual passenger flow is 80 million. Approximately 3,250 staff members have received cardiopulmonary resuscitation and AEDs skills training. Every year, Hangzhou City provides 150,000 people with basic training in cardiopulmonary resuscitation and the use of automatic external defibrillators.

\section{Number and location of AEDs}

May 2015 to December 2020, A total of 1201 AEDs are deployed in Hangzhou city (Figure 1: AEDs map), Among them, 10 AEDs are placed on the railway station. Defibrillation equipment is installed in waiting room and arrival exit. The AEDs is placed in a cabinet with a glass surface. The distance is about 3 minutes (Figure 2). There are obvious signs next to the defibrillator, Warning signs indicate that AEDs cannot be moved or improperly used. The cabinet is equipped with audible alarms and strobe lights. These devices are activated when the cabinet door is opened.

It uses the defibrillator (Bernhardt D1 Pro) produced by Mindray, working principle adopts biphasic wave defibrillation technology. Each electric shock produces about 150 joules of energy. Defibrillation mode selection is divided into adults and children. After defibrillation, there will be a voice prompt function of pressing rhythm during CPR. At the same time, the electrocardiogram is displayed on the LCD screen of the AEDs. The AED's LCD screen displays the electrocardiogram.

\section{AEDs data}

The digital data card in the defibrillator will record the ECG data. Machine prompts, the energy of the electric

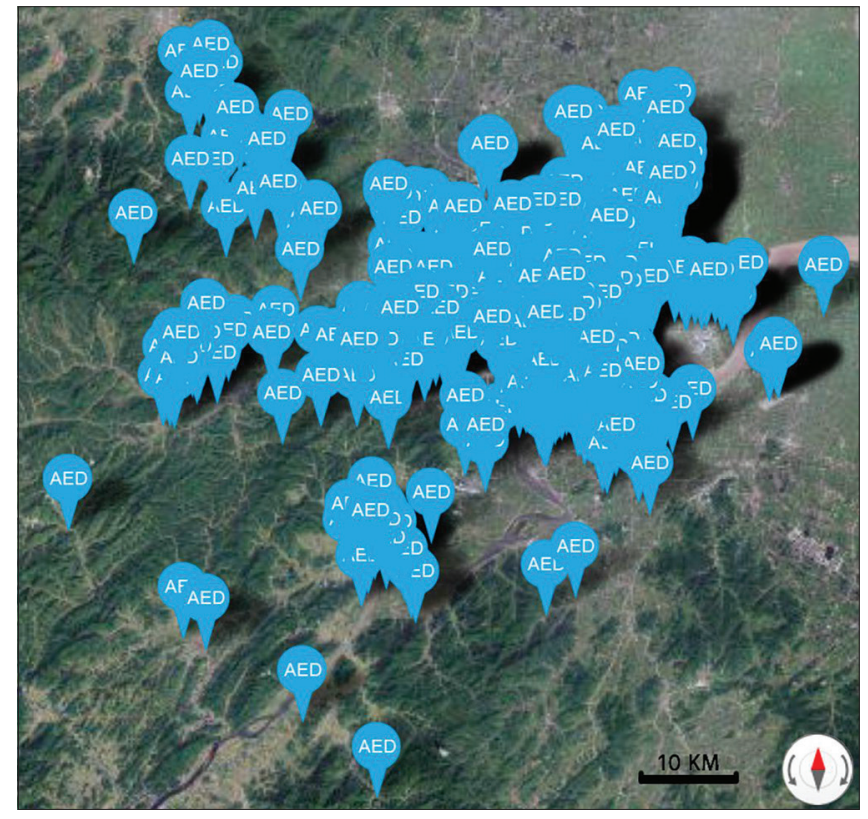

Figure 1: AEDs map of part of Hangzhou city

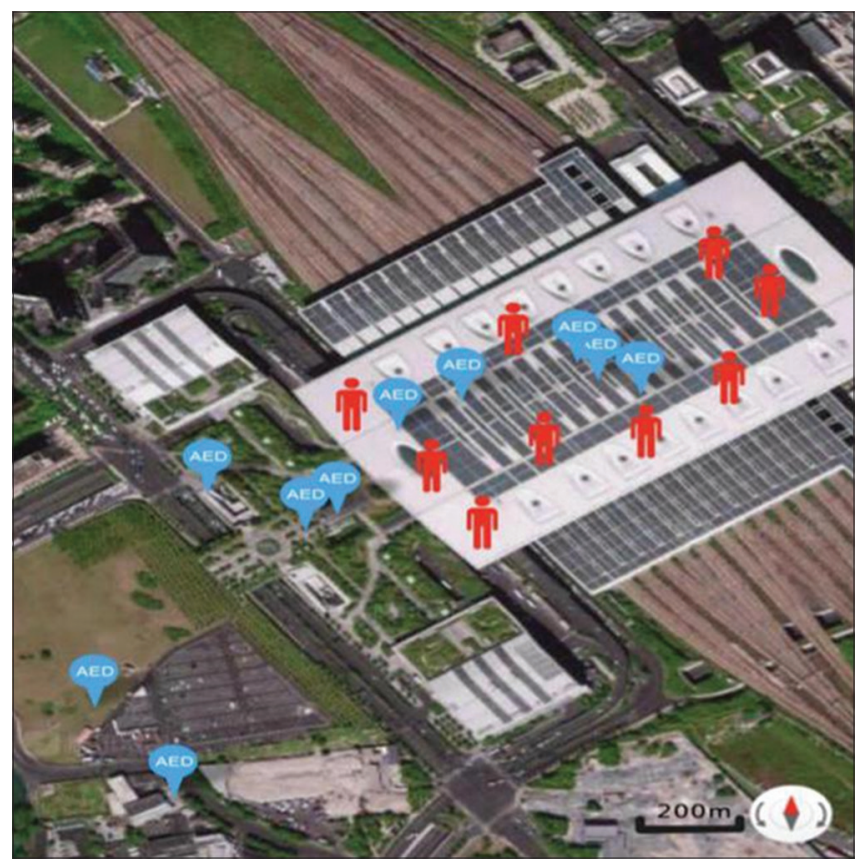

Figure 2: The location of the train station AED and the location of 9 patients with cardiac arrest

shock, and the time of all events the actual time of cardiac arrest cannot be determined, However, when the AEDs is used, it will record the time from the bystander (for example, by opening the door of the defibrillator cabinet) to the first shock, the initial heart rhythm, the number of shocks, and the recovery of spontaneous circulation. Information about whether bystanders have performed cardiopulmonary resuscitation, the patient's 
condition data is obtained from the records of emergency personnel.

\section{Statistical methods}

Spss20.0 software was used for analysis, All data were tested for normality.Normally distributed data is represented by the mean,Non-normal data is represented by the median.

\section{RESULTS}

\section{AEDs configuration and use}

As the AEDs configuration increases, it has become easier for patients with cardiac arrest to obtain AEDs, and the number of uses has increased. The number of AEDs in public areas has increased from 15 in to 1201in 2020. The proportion of patients who received public AEDs electric shock defibrillation due to cardiogenic ventricular fibrillation arrest witnessed by bystanders increased, Increase from $0.14 \%$ in (2 out of 1402 patients) to $0.46 \%$ in 2020 (7 out of 1520 patients) (Figure 3).

\section{Clinical features}

In 5 years, a total of 1201 AEDs were deployed in the public areas of Hangzhou city, provided 32 rescue behaviors for pre-hospital cardiac arrest patients. The average age of the patients was $40.56 \pm 17.20$, and the male to female ratio was 3.57:1. Among them, the initial rhythm of 26 cases was ventricular fibrillation, 3 cases were PEA, 1 case was ventricular arrest, 1 case was supraventricular arrhythmia, and 1 case was normal sinus rhythm. All 26 patients with ventricular fibrillation received AED electric shock defibrillation. The remaining 6 cases were not given electric shocks when the defibrillators were operating normally. The median time of initial defibrillation provided by the AEDs for defibrillating heart rhythms is 62.5 (40.25)'S (Table 1).

\section{Effect of defibrillation}

Automated external defibrillators can work normally in all 32 patients with ventricular fibrillation. Immediately determine whether an electric shock is required and perform electric shock defibrillation. In all patients, the AEDs was operated by witnesses or airport staff before the arrival of emergency medical services. Among the 32 patients with cardiac arrest, 26 had ventricular fibrillation whose initial heart rhythm was ventricular fibrillation, and Return of spontaneous circulation (ROSC) at the scene after defibrillation by electric shock in 6 patients indicated failure to defibrillate, and 4 patients never had a defibrillating rhythm. On-site cardiopulmonary resuscitation Non-Return of spontaneous circulation. Thirteen patients were defibrillated within 60 seconds after the AEDs was switched on. Despite the rapid use

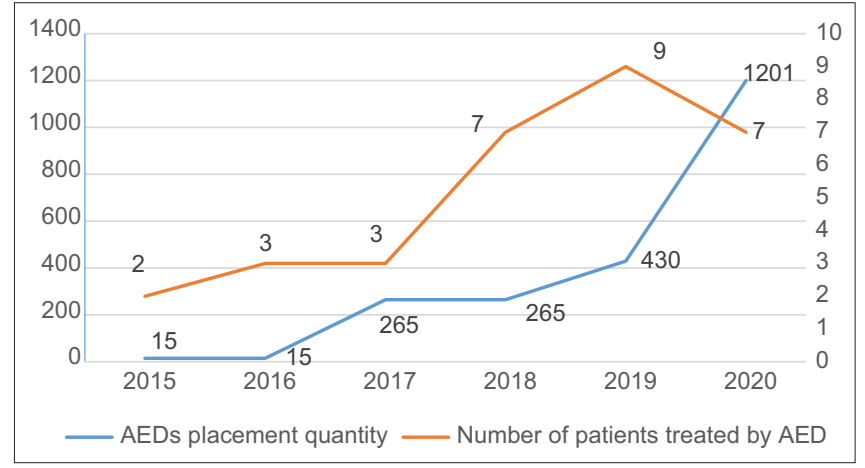

Figure 3: Configuration and treatment of AED in public areas

\begin{tabular}{|c|c|c|c|}
\hline & $\begin{array}{l}\text { Return of } \\
\text { spontaneous } \\
\text { circulation } \\
\text { (ROSC)(n) }\end{array}$ & $\begin{array}{l}\text { Non-Return of } \\
\text { spontaneous } \\
\text { circulation } \\
(\mathrm{N}-\mathrm{ROSC})(\mathrm{n})\end{array}$ & Total (n) \\
\hline \multicolumn{4}{|l|}{ Gender } \\
\hline Male & 18 & 7 & 25 \\
\hline Female & 4 & 3 & 7 \\
\hline \multicolumn{4}{|l|}{ Age } \\
\hline$<50$ years old & 13 & 8 & 21 \\
\hline$\geq 50$ years old & 9 & 2 & 11 \\
\hline \multicolumn{4}{|l|}{ Location } \\
\hline $\begin{array}{l}\text { Transportation } \\
\text { hub }\end{array}$ & 13 & 3 & 16 \\
\hline Other & 9 & 7 & 16 \\
\hline \multicolumn{4}{|l|}{ Initial rhythm } \\
\hline $\begin{array}{l}\text { Defibrillatory } \\
\text { rhythm }\end{array}$ & 17 & 9 & 26 \\
\hline $\begin{array}{l}\text { Non } \\
\text { defibrillator } \\
\text { rhythm }\end{array}$ & 5 & 1 & 6 \\
\hline \multicolumn{4}{|l|}{$\begin{array}{l}\text { Startup } \\
\text { defibrillation } \\
\text { time* }\end{array}$} \\
\hline$\leq 60$ seconds & 9 & 4 & 13 \\
\hline$>60$ seconds & 11 & 4 & 15 \\
\hline \multicolumn{4}{|l|}{$\begin{array}{l}\text { Defibrillation } \\
\text { times }\end{array}$} \\
\hline 0 & 2 & 2 & 4 \\
\hline 1 & 6 & 4 & 10 \\
\hline 2 & 5 & 1 & 6 \\
\hline$\geq 3$ & 9 & 3 & 12 \\
\hline
\end{tabular}

of defibrillators, four patients were still in persistent ventricular fibrillation and eventually died were 15 patients whose defibrillation time was more than 60 seconds, 11 patients Return of spontaneous circulation (ROSC) at the scene, One patient received initial defibrillation for 27 minutes; 12 patients received AED defibrillation more than 3 times. Before the arrival of pre-hospital first responders, four patients received 5 times of electric defibrillation (Table 1). 


\section{DISCUSSION}

In the past five years, the number of AEDs in public areas in Hangzhou city was 1201, The configuration standard is about 10 sets per 100000 people. There are 16.3 sets per 100000 people in the main urban area, there is still a considerable gap with Lu Chuanzhu et al., ${ }^{11}$ suggesting to follow the standard of "100 to 200 AEDs per 100,000 people". We found that the number of people using AEDs in public places increased. Most patients with ventricular fibrillation are resuscitated by witnesses within minutes, Witnesses immediately used the automatic defibrillator, On-site Return of spontaneous circulation (ROSC) to $67.7 \%$. We confirmed the previous evidence; Defibrillation in public places is associated with an increased probability of survival after out-of-hospital ventricular fibrillation cardiac arrest. ${ }^{12-14}$ In contrast, the estimated survival rate of traditional pre-hospital emergency medical service is still less than $1 \%$. Therefore, the start time of early electric shock defibrillation is an important factor affecting the success of cardiopulmonary resuscitation. ${ }^{15,16}$

All patients for this study received cardiopulmonary resuscitation and AEDs defibrillation; The shortest time of initial defibrillation in patients with cardiac arrest was 48 seconds; One patient received initial defibrillation 27 minutes after CPR, It shows that even trained witnesses, It also takes a while to deliver defibrillation, Witnesses who also did not receive basic training of cardiopulmonary resuscitation and AEDs, It may take a longer time to provide initial defibrillation. Sixteen cases of cardiac arrest occurred in the transportation hub, $50 \%$ of the total cases. Due to the timely and effective emergency response of witnesses at the scene, 13 patients successfully defibrillated and Return of spontaneous circulation (ROSC) on-site, Implementation of the AEDs promotion program in public places. It has an obvious effect to train the staff of railway station, subway and other transportation hubs with normal cardiopulmonary resuscitation and AEDs skills.

We also found that increasing the number of public AEDs and shortening the time of the first shock was positively correlated with the number of patients who survived; This is consistent with reported study of Kitamura $\mathrm{T}$ et al. ${ }^{17,18}$ For example, there are more AEDs in Hangzhou Railway Station, and the number of people treated and the success rate are significantly higher than those in other areas. According to the American Heart Association, guidelines13and-related AEDs placement strategy.

\section{Recommendations ${ }^{19,20}$}

AEDs can be obtained and used from any location in a public place within a 1.0 minute to 1.5 -minute walk. Although the number of AEDs in public places has increased in the past five years, but in most places the configuration of AEDs is still insufficient. Moreover, the relationship between the location of AEDs in public places and their effectiveness needs to be investigated, Many AEDs are located in buildings or other places that cannot be used at night or on weekends. ${ }^{21}$ This reduces the availability of a common automated external defibrillator. AEDs public planning process should be strengthened, training non-professionals. Establish a connection with the pre-hospital emergency system and a system for maintaining equipment and monitoring quality improvement. ${ }^{22}$

This study shows that the initial heart rhythm of $81.25 \%$ of patients with cardiac arrest is ventricular fibrillation. For all other initial rhythms, the AEDs was invalid and not programmed, and no defibrillation command was issued. For patients with the out-of-hospital cardiac arrest that cannot be defibrillated, AEDs defibrillation is not applicable or ineffective.

\section{CONCLUSION}

Public area AEDs is a comprehensive program; It requires careful planning and supervision of government departments, relevant public training, and quality management. To maximize the effectiveness of these projects, the reasonable public health strategy is to formulate the standard of AEDs allocation in public areas and corresponding regulations. Encourage the development of more intelligent automatic external defibrillators. They should be installed in a suitable public area. ${ }^{23}$ There should be a training program to promote everyone's ability to take immediate action in an emergency. ${ }^{24}$ Increasing the incidence of ROSC and the survival rate after discharge from the hospital is essential to improve the prognosis of patients with cardiac arrest. ${ }^{24}$

\section{LIMITATIONS OF THIS STUDY}

First, we only obtained data on cases where AEDs were used in public places and caused electric shocks. Second, there is a lack of information about bystanders who use AEDs, including those who witnessed out-of-hospital cardiac arrest and electrical shocks. Third, as with all epidemiological studies, data integrity and validity are potential limitations of our study.

\section{ACKNOWLEDGEMENT}

We thank all the organizations that allocate the resources for AEDs and make AEDs accessible to the public for 
saving the lives. We thank Ms. Lu Meili of Hangzhou for her very important support.

\section{REFERENCES}

1. Shao F, Li CS, Liang LR, Li D and Ma SK. Outcome of out-ofhospital cardiac arrests in Beijing, China. Resuscitation. 2014; 85:1411-1417.

https://doi.org/10.1016/j.resuscitation.2014.08.008

2. Zhang S. Sudden cardiac death in China: current status and future perspectives. Europace. 2015; 17: ii14-8.

https://doi.org/10.1093/europace/euv143

3. Cummins RO, Ornato JP, Thies WH and Pepe PE. Improving survival from sudden cardiac arrest: the "chain of survival" concept. A statement for health professionals from the Advanced Cardiac Life Support Subcommittee and the Emergency Cardiac Care Committee, American Heart Association. Circulation. 1991; 83:1832-1847.

https://doi.org/10.1161/01.cir.83.5.1832

4. Nielsen AM, Folke F, Lippert FK and Rasmussen LS. Use and benefits of public access defibrillation in a nation-wide network. Resuscitation. 2013; 84:430-434.

https://doi.org/10.1016/j.resuscitation.2012.11.008

5. Pollack RA, Brown SP, Rea T, Aufderheide T, Barbic D, Buick JE, et al. Impact of bystander automated external defibrillator use on survival and functional outcomes in shockable observed public cardiac arrests. Circulation. 2018; 137:2104-2113.

https://doi.org/10.1161/circulationAHA.117.030700

6. Deakin CD, Shewry E and Gray HH. Public Access Defibrillation remains out of reach for most victims of out-of-hospital sudden cardiac arrest. Heart. 2014; 100:619-623.

https://doi.org/10.1136/heartjnl-2013-305030

7. Wissenberg M, Lippert FK, Folke F, Weeke P, Hansen CM, Christensen EF, et al. Association of national initiatives to improve cardiac arrest management with rates of bystander intervention and patient survival after out-of-hospital cardiac arrest. JAMA. 2013; 310:1377-1384.

https://doi.org/10.1001/jama.2013.278483

8. Hallstrom AP, Ornato JP, Weisfeldt M, Travers A, Christenson J, McBurnie MA, et al. Public-access defibrillation and survival after out-of-hospital cardiac arrest. N Engl J Med. 2004;351(7)637-646. https://doi.org/10.1056/NEJMoa040566

9. Bækgaard Josefine S, Viereck S, Møller Thea P, Ersbøll Annette K, Lippert F and Folke F. The effects of public access defibrillation on survival after out-of-hospital cardiac arrest. Circulation. 2017; 136:954-965.

https://doi.org/10.1161/CIRCULATIONAHA.117.029067

10. Garcia EL, Caffrey-Villari S, Ramirez D, Caron JL, Mannhart P, Reuter PG, et al. [Impact of onsite or dispatched automated external defibrillator use on early survival after sudden cardiac arrest occurring in international airports]. Presse Medicale (Paris, France: 1983). 2017;46(3): e63-e68.

https://doi.org/10.1016/j.lpm.2016.09.027

11. Emergency medicine branch of Chinese Medical Association, island emergency medicine innovation unit of Chinese Academy of Medical Sciences (2019ru013), Key Laboratory of emergency and trauma research of Hainan Medical College, Ministry of education, etc. expert consensus on the layout and delivery of AED in China [J]. Chinese Journal of emergency medicine. 2020;29(8): 1025-1031. ISTIC PKU CSCD CA, 2020.

https://doi.org/10.13210/j.cnki.jhmu.20200729.003
12. Kitamura $\mathrm{T}$, Iwami $\mathrm{T}$, Kawamura $\mathrm{T}$, Nagao $\mathrm{K}$, Tanaka $\mathrm{H}$ and Hiraide A. Nationwide public-access defibrillation in Japan. $\mathrm{N}$ Engl J Med. 2010; 362:994-1004. https://doi.org/10.1056/NEJMoa0906644

13. Weisfeldt ML, Sitlani CM, Ornato JP, Rea T, Aufderheide TP, Davis D, et al. Survival after application of automatic external defibrillators before arrival of the emergency medical system: evaluation in the Resuscitation Outcomes Consortium population of 21 million. J Am Coll Cardiol. 2010; 55:1713-1720. https://doi.org/10.1016/j.jacc.2009.11.077

14. Baekgaard JS, Viereck S, Møller TP, Ersboll AK, Lippert F, Folke $F$, et al. The effects of public access defibrillation on survival after out-of-hospital cardiac arrest: a systematic review of observational studies. Circulation. 2017; 136(10): 954-965. https://doi.org/10.1161/circulationAHA.117.032513

15. Xiaogang $W$ and Ding $G$. The clinical experience of 505 cases of cardiopulmonary resuscitation in prehospital cardiac arrest patients and analysis of its success factors. Chinese Journal of Clinicians. 2015; 000(004):39-41. https://doi.org/CNKI:SUN:ZLYS.0.2015-04-017

16. Lixiang $W$, Qingyi $M$ and Tao $Y$. Chinese Expert Consensus on Cardiopulmonary Resuscitation. Medical Journal of Chinese People's Liberation Army. 2017; 42(03):243-269. https://doi.org/CNKI:SUN:JYZH.0.2017-01-003

17. Kitamura $\mathrm{T}$, Iwami $\mathrm{T}$, Kawamura $\mathrm{T}$, Nagao $\mathrm{K}$, Tanaka $\mathrm{H}$ and Hiraide A. Implementation Working Group for the All-Japan Utstein Registry of the Fire and Disaster Management Agency. Nationwide public-access defibrillation in Japan. N Engl J Med. 2010;362(11):994-1004.

https://doi.org/10.1056/NEJMoa0906644. PMID: 20237345

18. Pollack RA and Brown SP. Impact of Bystander Automated External Defibrillator Use on Survival and Functional Outcomes in Shockable Observed Public Cardiac Arrests. Circulation. 2018; 137 (20): 2104-2113.

https://doi.org/10.1161/circulationAHA.117.03070

19. Folke F, Lippert FK, Nielsen SL, Gislason GH, Hansen ML, Schramm TK, et al. Location of cardiac arrest in a city center: strategic placement of automated external defibrillators in public locations. Circulation. 2009; 120(6):510-517. https://doi.org/10.1161/circulationAHA.108.843755

20. Hazinski MF, Idris AH, Kerber RE, Epstein A, Atkins D, Tang W, et al. Lay rescuer automated external defibrillator ("public access defibrillation") programs: lessons learned from an international multicenter trial: advisory statement from the American Heart Association Emergency Cardiovascular Care Committee; the Council on Cardiopulmonary, Perioperative and Critical Care; and the Council on Clinical Cardiology. Circulation. 2005; 111:3336-3340.

https://doi.org/10.1161/circulationAHA.105.165674

21. Hansen CM, Wissenberg M, Weeke P, Ruwald MH, Lamberts M, Lippert FK, et al. Automated external defibrillators inaccessible to more than half of nearby cardiac arrests in public locations during evening, night time and weekends. Circulation. 2013; 128: 2224-2231.

https://doi.org/10.1161/circulationAHA.113.003066

22. Delhomme C, Njeim M, Varlet E, Pechmajou L, Benameur N, Cassan $\mathrm{P}$, et al. Automated external defibrillator use in outof-hospital cardiac arrest: Current limitations and solutions. Archives of cardiovascular diseases. 2019; 112(3): 217-222. https://doi.org/10.1016/j.acvd.2018.11.001

23. Zhang L, Li B, Zhao X, Zhang Y, Deng Y, Zhao A, et al. Public access of automated external defibrillators in a metropolitan city of China. Resuscitation. 2019; 140:120-126. 
https://doi.org/10.1016/j.resuscitation.2019.05.015

24. Barbic D, Grunau BE, Scheuermeyer FX, Dick W and Christenson J. LO70: Do automatic external defibrillators improve rates of return of spontaneous circulation, survival to hospital discharge and favourable neurological survival in Canada. Canadian Journal of Emergency Medicine. 2017; 19(S1):S52.

https://doi.org/10.1017/cem.2017.132

Author's Contribution:

JXS-Concept and design of the study; Interpreted the results; prepared first draft of manuscript; YK-Statistically analyzed and interpreted, revision of the manuscript; ZG-Concept, coordination, review of literature; ZH-Reviewed the literature and manuscript preparation.

Work Attributed to:

Medical Emergency Service of Wenzhou, Zhejiang Province, China

Orcid ID:

Prof. Dr. Jin Xiao Sheng- (iD https://orcid org/0000-0002-8042-9506

Dr. Ye Kan- (10) https://orcid.org/0000-0002-6615-565X

Dr. Zhang Gai- io https://orcid.org/0000-0002-4161-1356

Dr. Zhang Hao- io https://orcid org/0000-0002-8247-7456 